\title{
Clinical and pathological study of ischaemic neuropathy
}

\author{
ROSEMARY A. EAMES AND L. S. LANGE \\ From the Department of Anatomy, St. Mary's Hospital Medical School, and the Department of \\ Neurology, St. Mary's Hospital, Paddington, London
}

For many years a number of workers have studied the relation between arterial occlusion or compression in man, produced by various pathological processes, and peripheral nerve abnormality. The whole subject was authoritatively reviewed by Richards (1951). There is ample evidence, clinical, histological, and electrical, that ischaemia of a nerve has an adverse effect upon it. Persisting nerve damage from ischaemia may be produced by arterial injury (Tinel, 1917; Holmes, Highet and Seddon, 1944), by embolism (Blackwood, 1944; Haimovici, 1950), by chronic occlusive arterial disease (Joffroy and Achard, 1889; Priestley, 1931; Hutchinson and Liversedge, 1956; Gairns, Garven, and Smith, 1960), by polyarteritis nodosa (Kernohan and Woltman, 1938), and by other, rarer, causes. Experimentally ischaemia has been produced in animal nerves by various means (Adams 1943; Roberts, 1948) and electrical studies have been carried out on ischaemic nerves (Bentley and Schlapp, 1943; Porter and Wharton, 1949). Lewis, Pickering, and Rothschild (1931) showed in their classical experiments that changes may be produced in nerve function by ischaemia.

The histological changes described in the nerves have been fairly consistent and non-specific, and involve patchy degeneration in nerve fibres together with endoneurial fibrosis. However, many reports have not distinguished between changes occurring in nerves after an acute ischaemic episode and those resulting from chronic longstanding ischaemia, and no attempt has been made to determine the type of degeneration in ischaemic nerve fibres by individual examination. In addition, many of the earlier reports on nerves in arteriosclerotic limbs were from cases complicated by diabetes mellitus. Some of the studies also were carried out on digital nerves, but it has been shown (Gairns et al., 1960) that the digital nerves even of healthy young subjects may reveal damage due to repeated minor injuries.

The state of the vasa nervorum in peripheral arteriosclerosis has been commented upon incidentally by a few authors while studying the nerves
(Joffroy and Achard, 1889; Woltman and Wilder, 1929). Cottrell (1940) found occlusive changes present in the vasa nervorum of the aged. Detailed examination of the smaller vessels has, however, been neglected both by workers on nerve ischaemia and by those studying arteriosclerosis.

It has been shown that there are two types of degenerative change that occur in nerve fibres: Wallerian degeneration and segmental demyelination (Gombault, 1880; Vizoso and Young, 1948; Thomas and Young, 1949; Vizoso, 1950; Lubińska, 1958 and 1959). It is a common clinical experience to find abolition of vibration sensitivity and diminution or loss of ankle jerks in the feet of the aged (Pearson, 1928; Critchley, 1931). Lascelles and Thomas (1966) studied isolated nerve fibres from the sural nerves of subjects of various ages, and found degenerative changes present in those over the age of 65 years, segmental demyelination being the predominant abnormality. They suggested a possible relationship between these clinical findings and nerve changes and atheromatous occlusion of the vasa nervorum.

The present investigation was designed to determine the degree of neurological abnormality, as assessed clinically, in the affected limbs of patients with chronic occlusive arterial disease of the legs. This was combined with a study of the pathological changes in sensory nerves from the affected limbs, by both light and electron microscopy, with particular reference to the alterations in the vasa nervorum and the detailed study of the nerve fibres themselves.

\section{MATERIALS AND METHODS}

CLINICAL SURVEY Thirty-two patients with clear clinical and arteriographic evidence of peripheral arterial disease of the lower limbs were studied. Two patients were suffering from Buerger's disease, with histories dating back 27 and 13 years respectively, and the other 30 patients had arteriosclerotic obliterative disease. All were in-patients, admitted under the care of the Surgical Unit for surgery (endarterectomy, sympathectomy, by-pass procedures, or amputation). Their ages ranged from 
43 to 71 years, 28 patients falling into the 50-to-70-year range (Table I). Twenty-six patients were smokers, and, with one exception, all were male.

\section{TABLE I}

AGES OF PATIENTS AND DURATION OF SYMPTOMS OF PERIPHERAL ARTERIAL DISEASE

\begin{tabular}{|c|c|c|}
\hline Patient & $\begin{array}{c}\text { Duration of Symptoms } \\
\text { (years) }\end{array}$ & Age (years) \\
\hline 1 & 1 & 71 \\
\hline 2 & 2 & 71 \\
\hline 3 & 2 & 55 \\
\hline 4 & 27 & 53 \\
\hline 5 & $1 \frac{1}{2}$ & 57 \\
\hline 6 & $\frac{1}{2}$ & 59 \\
\hline 7 & 3 & 64 \\
\hline 8 & 13 & 43 \\
\hline 9 & 4 & 52 \\
\hline 10 & 3 & 64 \\
\hline 11 & 1 & 52 \\
\hline 12 & 11 & 58 \\
\hline 13 & 7 & 65 \\
\hline 14 & 2 & 52 \\
\hline 15 & 10 & 65 \\
\hline 16 & 3 & 68 \\
\hline 17 & 3 & 65 \\
\hline 18 & 5 & 63 \\
\hline 19 & 7 & 62 \\
\hline 20 & 7 & 65 \\
\hline 21 & 1 & 59 \\
\hline 22 & $\frac{1}{2}$ & 60 \\
\hline 23 & 5 & 63 \\
\hline 24 & 1 & 70 \\
\hline 25 & 7 & 71 \\
\hline 26 & 5 & 50 \\
\hline 27 & 2 & 61 \\
\hline 28 & 4 & 68 \\
\hline 29 & $1 \frac{1}{2}$ & 62 \\
\hline 30 & $1 \frac{1}{2}$ & 69 \\
\hline 31 & $2 \frac{1}{2}$ & 50 \\
\hline 32 & 3 & 57 \\
\hline
\end{tabular}

Every effort was made to exclude patients with other possible causes of peripheral neuropathy or myelopathy, particularly diabetes, carcinoma, collagen diseases, a history of alcoholism or of neurotoxic drugs, vitamin deficiencies, and lumbar disc prolapse. In addition patients with a recent cerebrovascular accident or a family history of neurological disease were excluded. Apart from exclusions on those grounds no selection was made.

Each patient was carefully examined by one of us, particular attention being paid to the peripheral nervous system. Careful note was made of complaints of paraesthesiae or leg weakness, and the sensory examination was made as objectively as possible, in most cases the findings being confirmed on more than one occasion. Gangrenous areas were excluded from sensory testing.

Intermittent claudication was severe in all the patients, the least affected being able to walk a distance of up to 200 yards before pain forced them to stop. Thirteen patients had gangrene of the toes or feet, and 16 patients had pain at rest.

Twelve control patients were also examined. These were in hospital for various reasons. They were in a similar age range to the patients with arterial disease. None had any evidence of ischaemia of the lower limbs, and exclusions were made on the same basis as for the patients with vascular disease.

LIGHT AND ELECTRON MICROSCOPY Eight of the 32 patients with arterial disease had amputations at the knee joint while in hospital. All eight were biopsied for electron microscopy; five of these also had pieces of nerve taken for light microscopy. At operation a 2 in. incision was made 1 in. behind the lateral malleolus immediately before the leg was amputated. A small piece of sural nerve was removed and divided into three portions.

The larger piece was placed in a solution of $4 \%$ formaldehyde in $0.9 \%$ sodium chloride for four days. It was then transferred to a solution of $1 \%$ osmium tetroxide for 24 hours, washed in distilled water, and macerated in a solution of 2:1 glycerol and water for three days. Individual fibres were teased out in pure glycerol with mounted needles under a dissecting microscope and transferred to a few drops of creosote on a slide. For each case, the first 45 fibres covering the range of fibre diameter were teased out, no effort being made to obtain particularly pathological fibres. The nerve fibres were arranged in parallel rows, and, after draining off the creosote, mounted in Canada balsam.

Internodal length and fibre diameter were measured using a micrometer eyepiece; each diameter recorded was the mean of five measurements made along the internode. For each case, internodal lengths were plotted againsto the diameter of the widest internode on a given fibre, and the points joined by a vertical line, according to the method suggested by Fullerton, Gilliatt, Lascelles, and MorganHughes (1965).

The second piece of sural nerve obtained at amputation was placed in Flemming's fixative for 24 hours and, aftero washing and dehydration in alcohols, embedded in paraffin wax. Transverse sections were cut at $5 \mu$ and stained in Kulschitsky's stain for myelin by the method of Gutmann and Sanders (1943).

The smallest piece of nerve obtained was placed immediately in ice-cold $2 \%$ osmium tetroxide, buffered

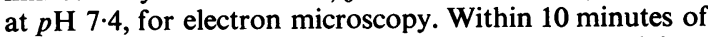
being placed in the fixative, the nerve was teased into individual fascicles with a sharp scalpel blade. After two to three hours of fixation, the pieces were placed in $70 \%$ alcohol for 12 hours, dehydrated in absolute alcohol, and embedded in Araldite. A few fascicles from each case were stained in bulk in $1 \%$ phosphotungstic acid in $95 \%$ alcohol before dehydrating.

Sections were cut using a Cambridge ultramicrotome, mounted on unfilmed copper grids, and examined in a Siemens Elmiskop I. Sections from those blocks which had not been stained in bulk were treated with lead hydroxide on the grid before examination.

\section{RESULTS}

CLINICAL FINDINGS Table II summarizes the abnormalities found, and shows a correlation between the incidence of neurological abnormalities and the severity of ischaemia. All patients with claudication distances of less than 100 yards showed 
TABLE II

SUMMARY OF CLINICAL FINDINGS

\begin{tabular}{|c|c|c|c|c|c|}
\hline Patient & Leg & $\begin{array}{l}\text { Pulses } \\
\text { Present }^{1}\end{array}$ & $\begin{array}{l}\text { Sensory } \\
\text { Deficit }^{2}\end{array}$ & $\begin{array}{l}\text { Ankle } \\
\text { Jerks }^{3}\end{array}$ & $\begin{array}{l}\text { Motor } \\
\text { Signs }^{4}\end{array}$ \\
\hline 1 & $\mathbf{R}$ & $F$ & a & + & - \\
\hline \multirow[t]{2}{*}{2} & $\begin{array}{l}\mathrm{L} \\
\mathbf{R}\end{array}$ & $\begin{array}{l}F \\
\text { All }\end{array}$ & $\begin{array}{l}\mathbf{a} \\
\mathbf{a}\end{array}$ & $\stackrel{+}{+}$ & $\overline{-}$ \\
\hline & L & $\mathrm{F}$ & c & + & + \\
\hline \multirow[t]{2}{*}{3} & $\mathbf{R}$ & $\underset{F}{F, D P}$ & $\overrightarrow{\mathrm{b}}$ & $\stackrel{R}{R}_{+}^{+}$ & $\bar{z}$ \\
\hline & $\mathbf{R}$ & $\mathbf{F}$ & c & + & - \\
\hline 5 & $\mathbf{R}$ & F, PT & - & $\mathbf{R}$ & - \\
\hline \multirow[t]{2}{*}{6} & $\mathbf{R}$ & $\begin{array}{l}\text { None } \\
\mathrm{F}\end{array}$ & a & + & \pm \\
\hline & $\mathrm{L}$ & All & - & + & - \\
\hline \multirow[t]{2}{*}{7} & $\mathrm{R}$ & $F$ & - & + & - \\
\hline & L & None & d & + & + \\
\hline \multirow[t]{2}{*}{8} & $\mathbf{R}$ & $F$ & - & + & - \\
\hline & L & All & - & + & - \\
\hline 9 & $\begin{array}{l}\mathbf{R} \\
\mathbf{L}\end{array}$ & $\begin{array}{l}\mathbf{F} \\
\mathbf{F}\end{array}$ & $\begin{array}{l}b \\
b\end{array}$ & + & $\bar{z}$ \\
\hline \multirow[t]{2}{*}{10} & $\mathbf{R}$ & $\mathrm{F}$ & a & + & - \\
\hline & $\mathbf{L}$ & $\mathbf{F}$ & a & + & - \\
\hline \multirow[t]{2}{*}{11} & $\mathbf{R}$ & $\mathbf{F}$ & a & + & -. \\
\hline & $\begin{array}{l}\mathbf{L} \\
\mathbf{R}\end{array}$ & $\begin{array}{l}F \\
F\end{array}$ & b & + & $=$ \\
\hline 12 & $\hat{\mathbf{L}}$ & $\mathrm{F}$ & - & -1. & - \\
\hline \multirow[t]{2}{*}{13} & $\mathbf{R}$ & $\mathbf{F}, \mathbf{P}$ & a & + & - \\
\hline & $\begin{array}{l}\mathbf{L} \\
\mathbf{R}\end{array}$ & $\begin{array}{l}\mathbf{F} \\
\mathbf{F}, \mathbf{P}\end{array}$ & c & $\begin{array}{l}+ \\
+\end{array}$ & \pm \\
\hline 14 & $\begin{array}{l}\mathbf{k} \\
\mathbf{L}\end{array}$ & None & b & + & + \\
\hline \multirow[t]{2}{*}{15} & $\mathbf{R}$ & $\mathrm{F}$ & a & $\mathbf{R}$ & - \\
\hline & $\mathbf{L}$ & F & a & $\mathbf{R}$ & - \\
\hline \multirow[t]{2}{*}{16} & $\mathbf{R}$ & F, DP & - & + & - \\
\hline & L & F, DP & - & + & - \\
\hline 17 & $\mathbf{R}$ & & $\bar{c}^{-}$ & $\stackrel{t}{-}$ & $\bar{t}$ \\
\hline \multirow[t]{2}{*}{18} & $\mathbf{R}$ & $\begin{array}{l}\text { None } \\
\text { None }\end{array}$ & d & $\mathbf{R}$ & - \\
\hline & L & $\mathbf{F}$ & a & + & - \\
\hline \multirow[t]{2}{*}{19} & $\mathbf{R}$ & $F$ & c & + & - \\
\hline & L & $\mathbf{F}$ & c & + & - \\
\hline \multirow{3}{*}{21} & L & None & d & - & + \\
\hline & $\mathbf{R}$ & $\mathbf{F}$ & a & $\mathbf{R}$ & - \\
\hline & L & $\mathbf{F}$ & d & $\mathbf{R}$ & + \\
\hline \multirow[t]{2}{*}{22} & $\mathbf{R}$ & $\mathbf{F}$ & d & + & + \\
\hline & $\begin{array}{l}\mathbf{L} \\
\mathbf{L}\end{array}$ & $\begin{array}{l}\text { All } \\
\mathbf{F}\end{array}$ & $\bar{d}$ & \pm & $\bar{t}$ \\
\hline \multirow{2}{*}{$\begin{array}{l}23 \\
24\end{array}$} & $\mathbf{R}$ & $\mathbf{F}$ & c & $\bar{R}$ & \pm \\
\hline & $\mathbf{L}$ & $\mathbf{F}$ & c & $\mathbf{R}$ & - \\
\hline 25 & $\mathbf{R}$ & $\mathbf{F}$ & d & + & + \\
\hline & $\begin{array}{l}\mathbf{L} \\
\mathbf{R}\end{array}$ & $\mathrm{F}$ & d & $\begin{array}{l}\mathbf{R} \\
\mathbf{R}\end{array}$ & \pm \\
\hline 26 & $\begin{array}{l}\mathbf{R} \\
\mathbf{L}\end{array}$ & $\begin{array}{l}F \\
F\end{array}$ & $\begin{array}{l}\text { b } \\
\text { b }\end{array}$ & $\begin{array}{l}\mathbf{R} \\
+\end{array}$ & $=$ \\
\hline 27 & $\mathbf{R}$ & $\mathrm{F}$ & b & + & + \\
\hline & L & $F$ & b & + & - \\
\hline 28 & $\mathbf{R}$ & $\mathbf{F}, \mathbf{P}$ & $\bar{b}$ & - & + \\
\hline & L & $\begin{array}{l}F \\
F, D P\end{array}$ & $\begin{array}{l}b \\
c\end{array}$ & - & \pm \\
\hline 29 & $\begin{array}{l}\mathbf{R} \\
\mathbf{L}\end{array}$ & $\underset{\mathrm{F}}{\mathrm{F}, \mathrm{DP}}$ & $\begin{array}{l}c \\
\text { c }\end{array}$ & $\overline{-}$ & - \\
\hline 30 & $\mathbf{R}$ & All & - & + & - \\
\hline & L & $F$ & a & + & + \\
\hline 31 & $\mathbf{R}$ & $\mathbf{F}$ & d & + & + \\
\hline & L & None & d & + & + \\
\hline 32 & $\begin{array}{l}\mathbf{R} \\
\mathbf{L}\end{array}$ & $\begin{array}{l}F \\
F\end{array}$ & $\begin{array}{l}c \\
c\end{array}$ & $\begin{array}{l}+ \\
+\end{array}$ & $\begin{array}{l}+ \\
+\end{array}$ \\
\hline
\end{tabular}

${ }^{1} \mathbf{F}=$ femoral pulse, $\mathbf{P}=$ popliteal pulse, $P T=$ posterior tibial pulse, DP $=$ dorsalis pedis pulse.

$\mathbf{2} \mathbf{a}=$ absent vibration sense, $\mathrm{b}=$ superficial sensory loss, $\mathrm{c}=$ absent vibration sense and superficial sensory loss, $d=$ impairment of all sensory modalities.

${ }^{8}$ Ankle jerks are recorded as present $(+)$, reduced $(\mathbf{R})$, or absent $(-)$. 'Positive motor signs indicate definite muscle weakness with or without wasting. some neurological abnormalities, which were severest in those who had pain at rest and claudication distances of 20 yards or less.

The presence of palpable pulses distal to the femoral pulse in these patients was usually associated with more minor degrees of neurological abnormality, or none at all. The site of major arterial occlusion did not appear to be related to the presence or severity of neuropathy. In 20 patients the superficial femoral artery was occluded, while in the remainder the occlusion was more proximal, although often associated with considerable atheroma distally.

Sensory abnormalities In $28(87.5 \%)$ patients one or more sensory modalities were impaired, vibration sensation alone in four. Faulty joint position sensation was demonstrable in nine patients, in all of whom superficial and vibration sensation was also impaired. Impaired superficial sensation varied from a patchy loss below the knee in 11 patients to an irregular stocking distribution of loss below the ankle or knee in one or both legs in 15 patients.

Paraesthesiae were present in 21 patients $(63 \%)$. The complaints were not prominent and were elicited by direct questioning, except in three patients, who complained spontaneously of bursts of sharp stabbing sensations resembling lightning pains.

Motor abnormalities Sixteen patients had weakness of one or both legs, and in 10 there was muscle wasting. Two of the patients with weakness had suffered recent acute episodes, and the pattern in one of them was that of a lateral popliteal nerve palsy following sudden occlusion of the common femoral artery. One patient (case 25) presented the picture of an almost symmetrical peripheral neuropathy affecting the legs for which no cause other than that of ischaemia could be found. In the others, the muscle wasting was diffuse and moderate in degree, present only in the more severely ischaemic limbs.

Reflex changes Thirteen patients had reduced or absent ankle jerks; those limbs in which the ankle jerks were merely reduced were not so ischaemic as those in which these reflexes were absent.

Control patients of the 12 control patients examined, only one had impaired vibration sense in the feet and sluggish ankle jerks.

LIGHT MICROSCOPY Figures 1 and 2 represent the relations between internodal length and fibre diameter in two of the cases where the nerve fibres were examined in this way. There are several prominent features of the graphs that differ from graphs made from normal subjects of similar ages. There is clear evidence that a considerable amount of 


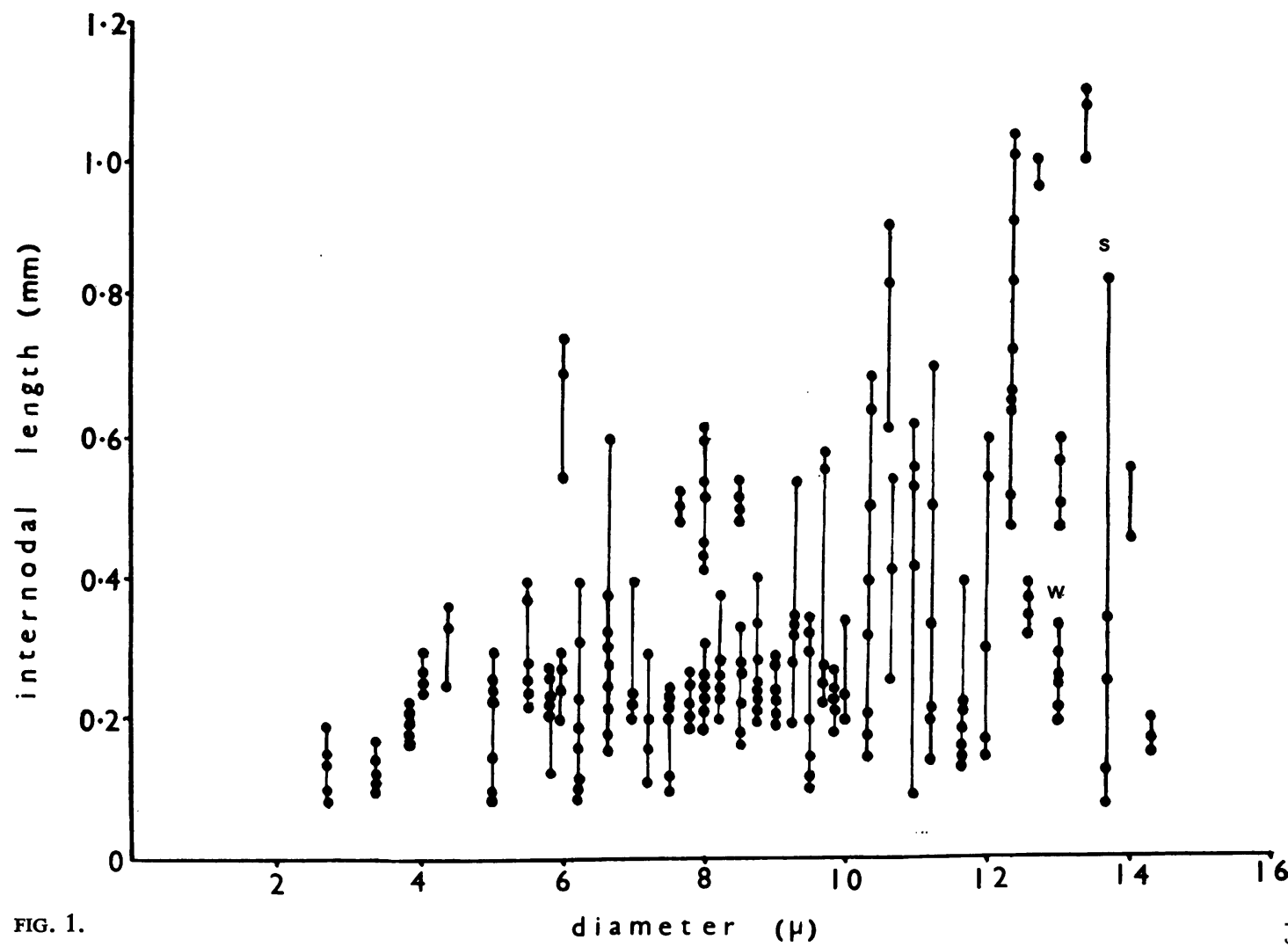

FIG. 1.

dia meter $(\mu)$

FIGS. 1 and 2. Graphs showing the relation between internodal length and fibre diameter (see text). Figure 1: case 21. $s=$ fibre showing evidence of segmental demyelination and remyelination; $w=$ fibre having undergone Wallerian-type degeneration and regeneration. Figure 2: case 31.

segmental demyelination and remyelination has occurred, as shown by the number of fibres present, with some internodes of normal length and others of very short length. This is shown most clearly in the fibres of widest diameter, but is also present in those of medium and small diameter. In addition a certain amount of Wallerian-type degeneration and regeneration has taken place; this is shown by the number of fibres in the medium and large diameter range which have uniformly short internodes.

In a normal subject in the age range being considered here, internodal length varies from approximately $0.15 \mathrm{~mm}$. at a diameter of $2 \mu$, to a length of approximately $1.0 \mathrm{~mm}$. at a diameter of $12 \mu$ (Lascelles and Thomas, 1966). In the cases described here, most internodal lengths for the fibres of medium and large diameter were considerably shorter than normal, with an average length of $0.70 \mathrm{~mm}$. at a diameter of $12 \mu$. In all cases, there were few fibres with internodal lengths greater than $0.80 \mathrm{~mm}$. While teasing the fibres, evidence of recent Wallerian degeneration could be seen in each case; this was most notable in the patient illustrated in Figure 1. In this case several endoneurial tubes containing scattered osmiophilic droplets were visible.

In a large number of fibres, abnormalities in the myelin sheath were apparent. These were of several types: (a) widening of the nodal gap (Fig. 3a); (b) demyelination over part of an internode, with apparently normal myelin on either side (Fig. 3b); (c) demyelination and partial remyelination over part of an internode (Fig. 3c); (d) demyelination and partial remyelination over one or more internodes (Fig. 3d). This last abnormality was the commonest type seen. Often the abnormalities alternated with normal segments on a single fibre. The demyelinated segments showed changes that ranged from complete disappearance of myelin to slight thinning only of the sheath. In the partially remyelinated segments, 


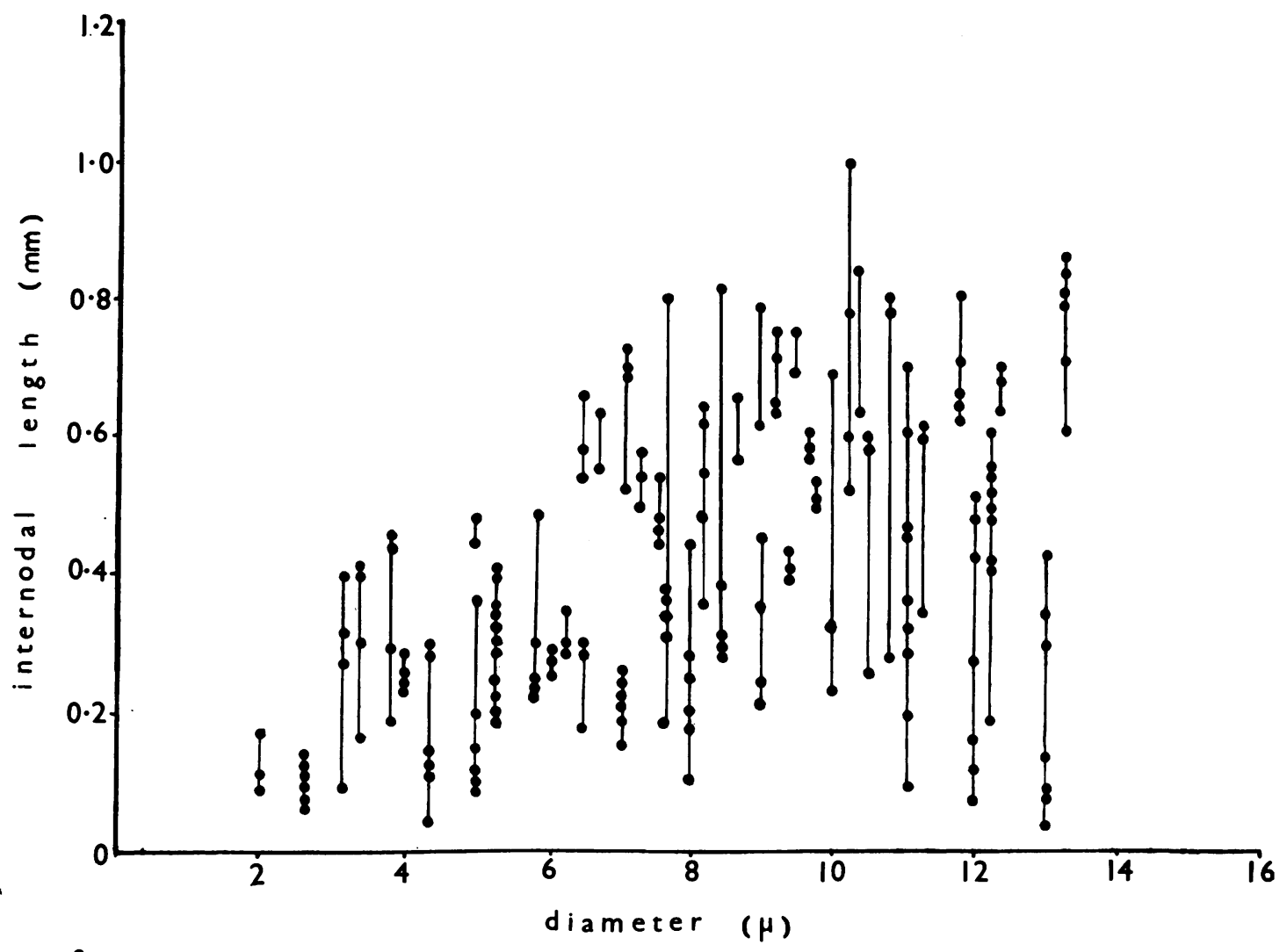

FIG. 2 .

Schmidt-Lantermann incisures were especially prominent.

These changes correspond with those previously described for nerve fibres undergoing segmental demyelination and remyelination.

Figure 4 shows a transverse section of an ischaemic nerve stained for myelin. The fibres are much less numerous than in a normal sural nerve from a subject of the same age (O'Sullivan, 1966), and some fibre loss was present in all the nerves examined.

The amount of endoneurial collagen was moderately increased in all cases, and the perineurium showed a probable slight increase in thickness. Both arterioles and small arteries of the interfascicular tissues showed thickening of their walls, with some endothelial proliferation. Many arterioles contained organized thrombus, and their lumens were occluded. The lumens of small arteries were reduced in diameter, and thrombi were also present in many of these vessels. collagen was present in the endoneurium of the nerves examined, and few large myelinated fibres were seen. Large numbers of Schwann cells were present, most of which contained many profiles of endoplasmic reticulum in their cytoplasm. In many Schwann cells there were cytoplasmic inclusions of homogeneous lipid-like material (Fig. 5), and the Golgi apparatus and ribosomes were prominent. Many Schwann cells contained lysosomes. Myelin figures and clumps of degenerate myelin within Schwann cells and processes were frequently seen (Fig. 6). Some Schwann cells entirely lacked an axon. Collagen pockets of the various types described by Gamble and Eames (1964) were seen in association with Schwann cells. Unmyelinated axons for the most part appeared normal (Fig. 5); some axons of both myelinated and unmyelinated fibres, however, showed loss of neurofibrils and contained large numbers of vacuoles and electron-dense vesicles. A few shrunken endoneurial tubes, consisting of Schwann cell processes surrounded by folded basement membranes, were present. Other endo- 


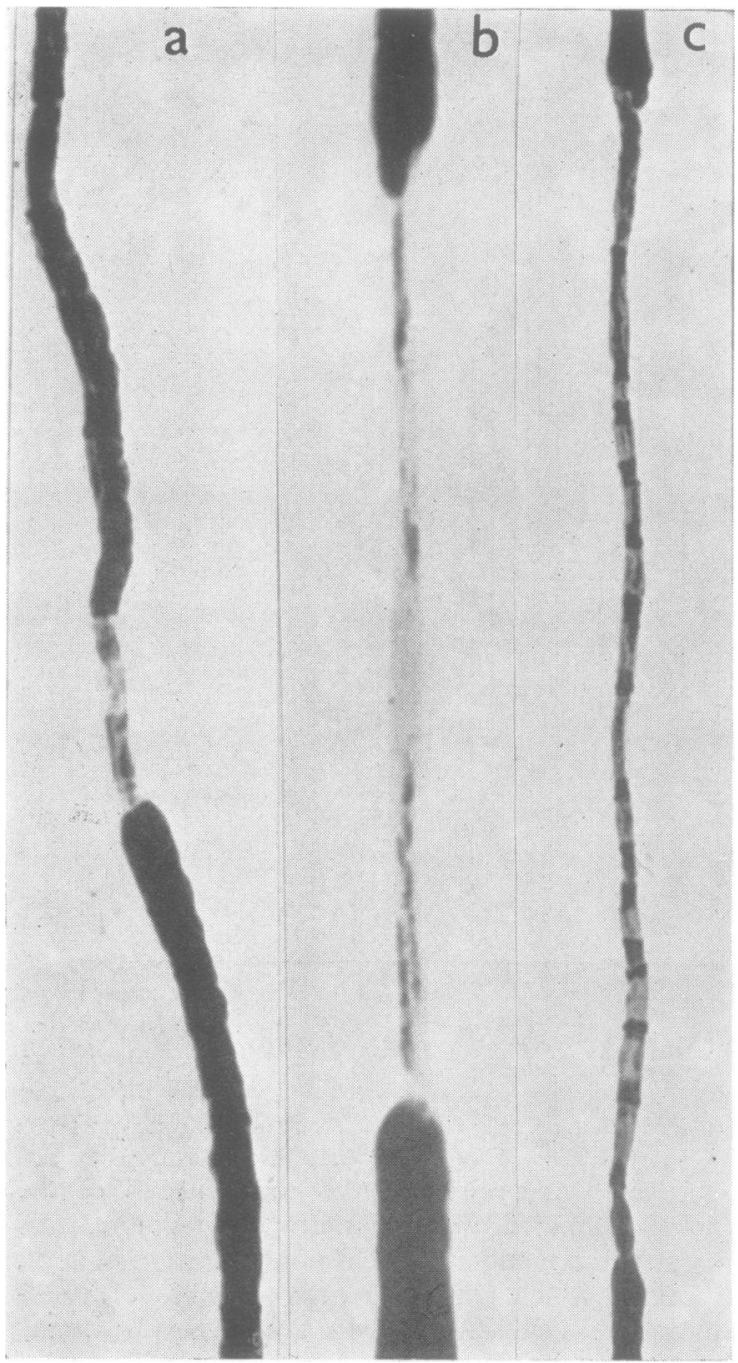

FIG. 3a. Portion of isolated nerve fibre showing widening of the nodal gap.

FIG. 3b. Part of fibre showing a short length of demyelination, with apparently normal myelin on either side.

FIG. 3c. Part of fibre showing a short length of incomplete remyelination, in which Schmidt-Lantermann incisures are prominent.
FIG. 3d. Nerve fibre showing a long segment of partial remyelination. It is not possible to distinguish the nodes of Ranvier.

The top end of $A$ is continuous with the lower end of $B$, and similarly through $C$ and $D$ to $E$.

Fibres stained with osmium tetroxide. Each $\times 600$. 


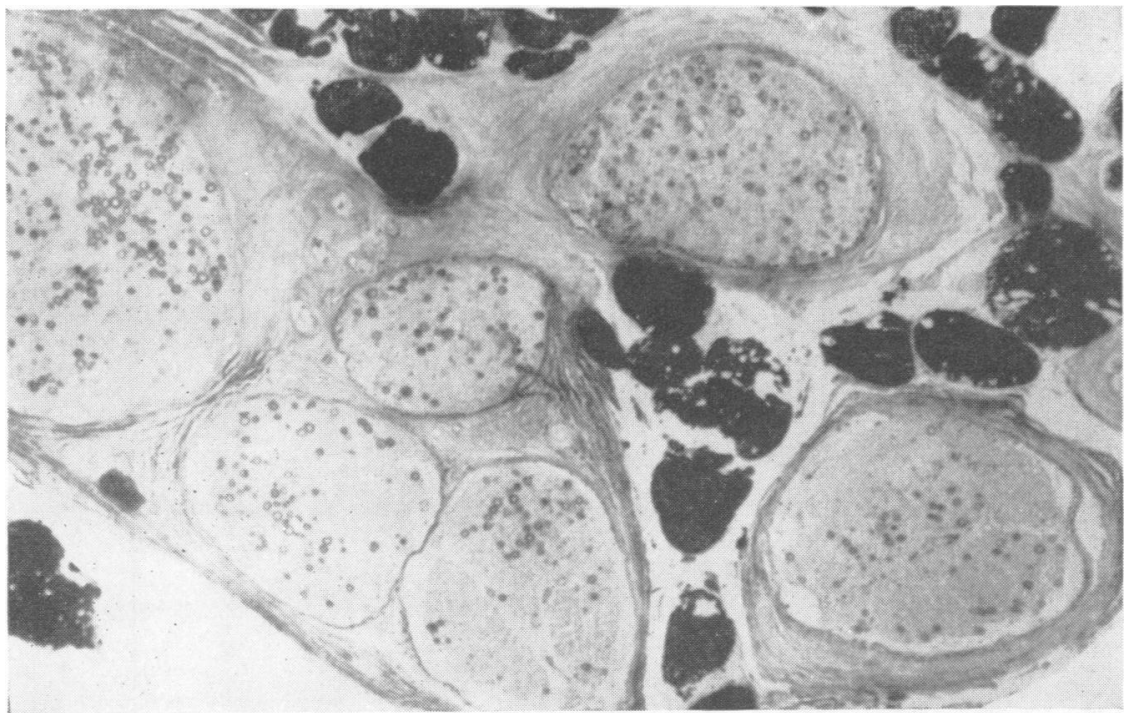

FIG. 4. Transverse section of sural nerve from case 21 , showing loss of myelinated fibres. Kulschitsky. $\times 60$.

FIG. 5. Electronmicrograph showing two nucleated Schwann cells with unmyelinated axons (a). The cytoplasm of both cells contains numerous vesicles, ribosomes $(\boldsymbol{r})$, and prominent Golgi apparatus $(G)$; and one cell also has three lipid-like inclusions (I). $N=$ Schwann nucleus. Lead hydroxide $\times 21,000$.

FIG. 4.

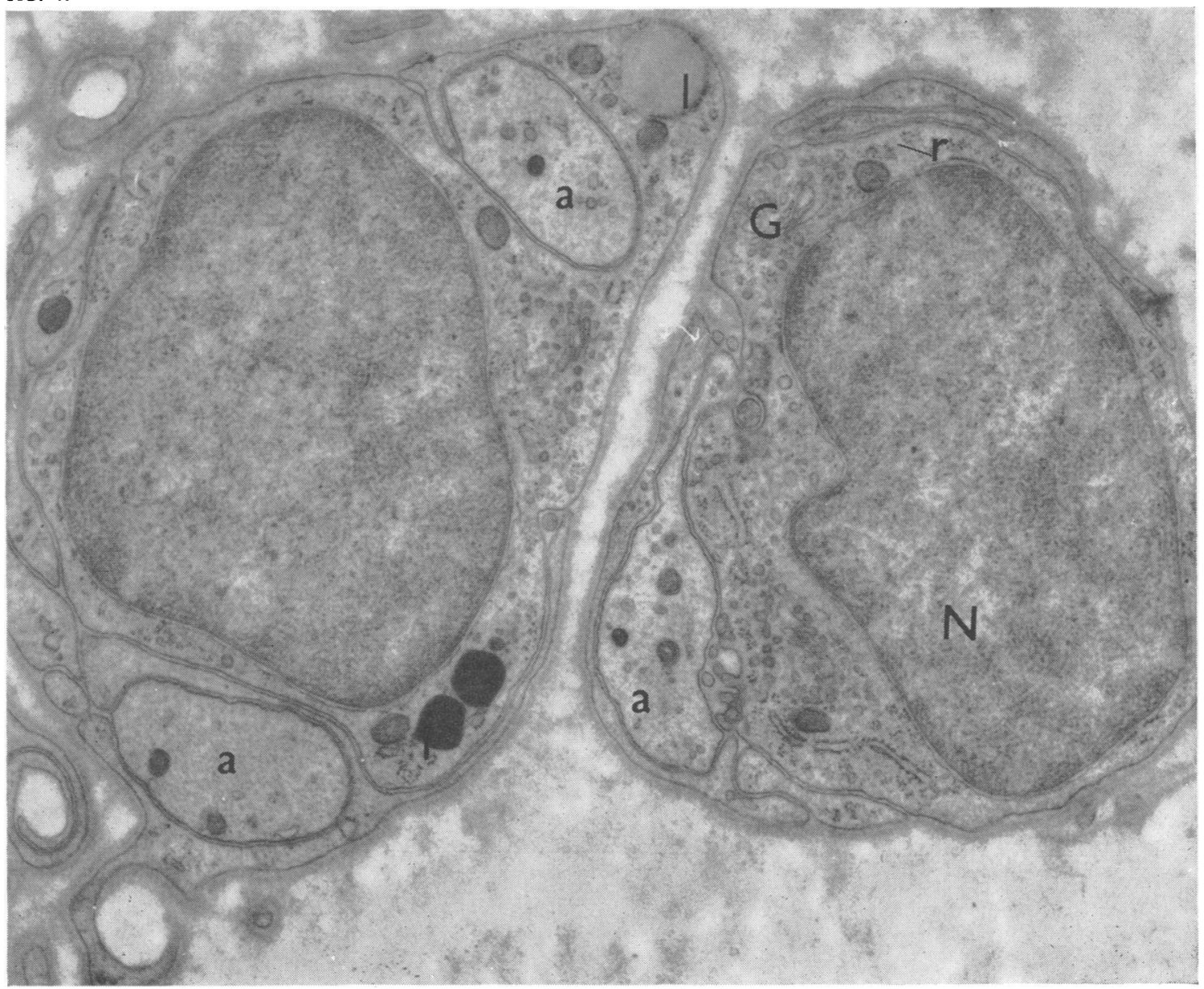

FIG. 5 . 


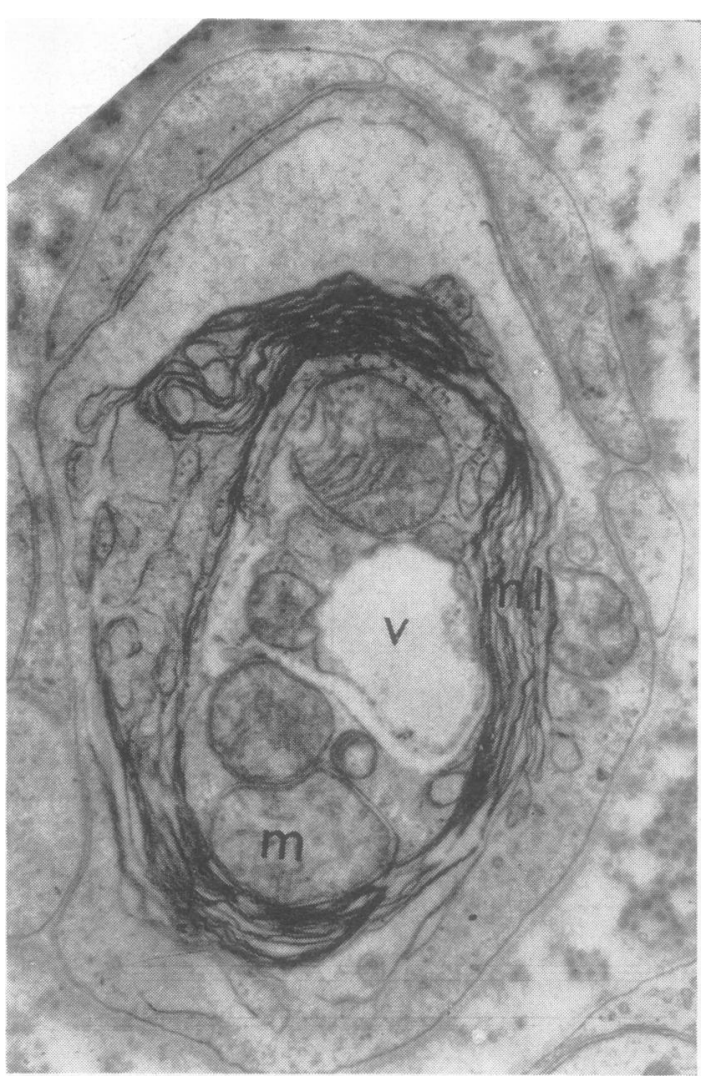

FIG. 6. Schwann cell process containing a myelin figure with lamellae $(\mathrm{ml})$ visible. The centre of the figure contains large mitochondria $(m)$ and a vacuole $(v)$. Lead hydroxide. $\times 20,000$.

neurial elements, fibroblasts and macrophages, were seen, the latter often containing myelin figures and lipid-like droplets.

The endoneurial capillaries were of particular interest. All those seen showed thickening of basement membranes (Fig. 7), often considerable. In many cases the basement membranes were multilayered (Fig. 8). An increase in pericapillary collagen was commonly present, sometimes forming a layer $3 \mu$ thick or even more (Fig. 9). Many endothelial cells showed irregular internal surfaces, with small villous projections into the vessel lumen, and lipid-like inclusions in the cytoplasm. Some capillaries consisted of several layers of endothelial cells; these were believed to have proliferated. Occasionally the lumen of a capillary was occluded by an electron-dense granular material resembling fibrin.

The epineurial tissue contained numbers of arterioles and capillaries. The latter were similar to

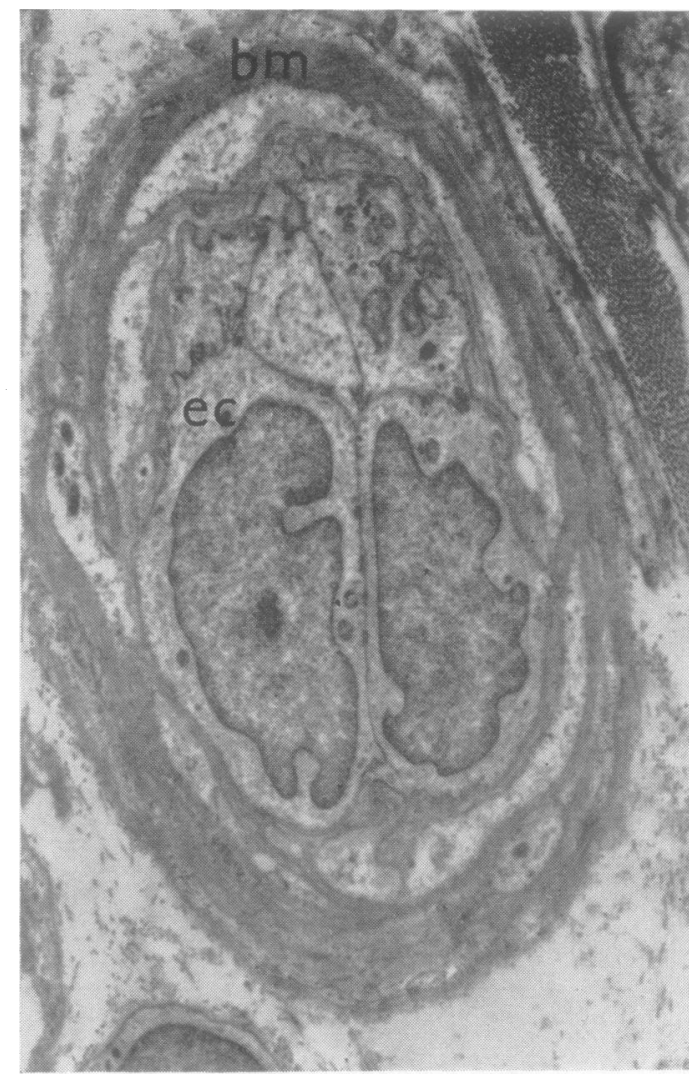

FIG. 7. Small endoneurial capillary in which the nucles of two endothelial cells $(e c)$ are visible. The endotheliat basement membranes (bm) are very thick. Phosphotungstic acid. $\times 2,000$.

those in the endoneurium. The arterioles showed marked abnormalities. The arteriolar lumen was often occluded by fibrin or by proliferated endothelial cells. Smooth muscle cells were vacuolated and of low electron density, with loss of myofilaments. Thickening of basement membranes was such as to resemble hyalinization in many areas, and small amounts of collagen were present between the cells of the media. In some vessels the medial layers appeared proliferated, and the cells contained homogeneous inclusions. Adventitial collagen was increased. Occasional small cellular constituents of the adventitia resembled Schwann cell processes, but contained no axons; these were believed to represent the Schwann cells of degenerate sympathetic nerve fibres.

A few small arteries were also present. Striking features in these were the abundance of intercellular collagen in the media and smooth muscle cells internal to the internal elastic lamina, often arranged 


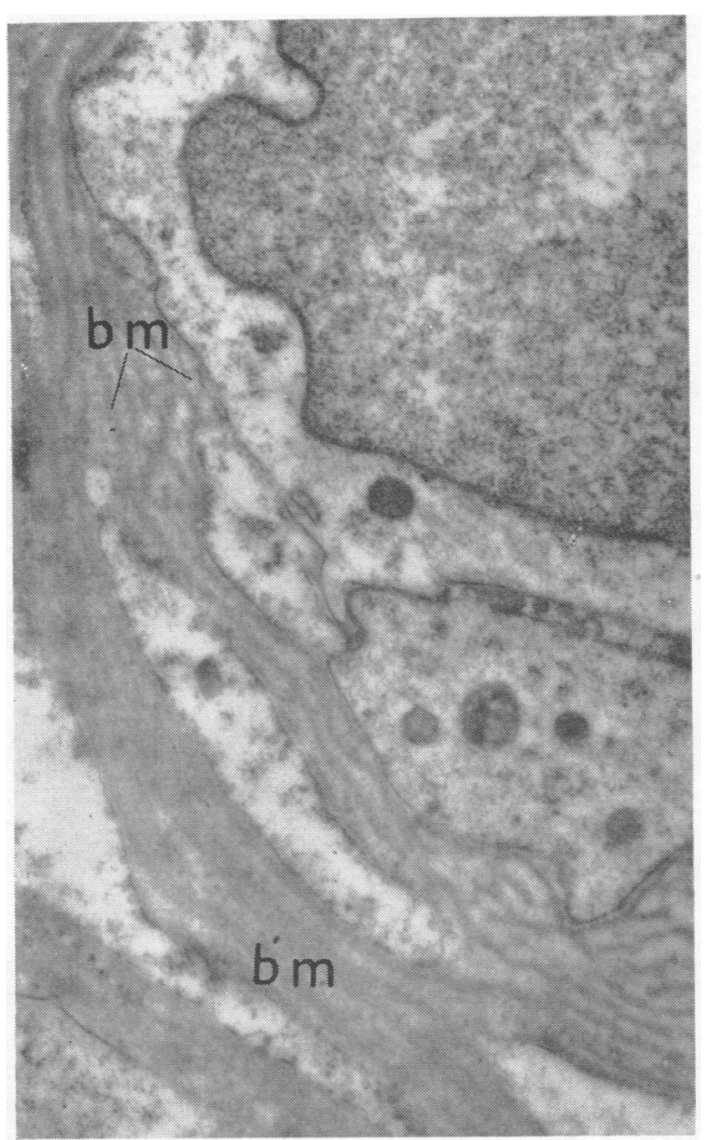

FIG. 8. Part of wall of endoneurial capillary showing proliferated basement membranes (bm). Phosphotungstic acid. $\times 18,000$.

in a concentric layer. This was associated with some fragmentation of the elastic sheets.

\section{DISCUSSION}

The incidence $(87.5 \%)$ of sensory neuropathy in this group of patients is considerably higher than that recorded by previous authors. Hutchinson and Liversedge (1956) found neurological abnormalities in $58.8 \%$ of patients and Mufson (1952) in $43 \%$. This discrepancy is most probably related to a greater severity of ischaemic disease in our patients, and to the fact that we have included estimates of vibration sensitivity. Lightning pains, painful paraesthesiae, and pain at rest were present in patients with more severe ischaemia, and in almost all these there was good evidence of sensory impairment. Richards (1951) has suggested that 'ischaemic neuritis' is

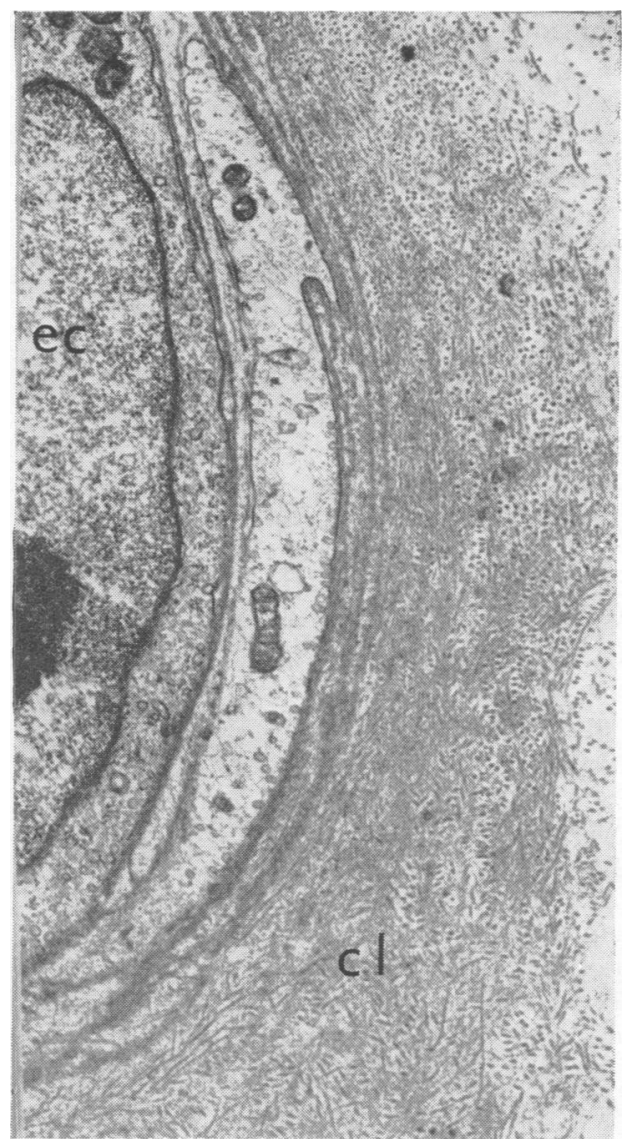

FIG. 9. Part of wall of endoneurial capillary showing grossly thickened perivascular collagenous layer ( $c l)$, up to $3 \mu$ thick. Lead hydroxide. $\times 15,000$.

seldom encountered where there is a short history of vascular disease. In our patients, however, five out of six limbs in which the history of claudication was under six months had evidence of sensory impairment, suggesting that severity of ischaemia is more important than length of history in the aetiology of neurological abnormalities.

The subject of the blood supply of peripheral nerves has received considerable attention for some years, and was reviewed by Adams (1942) and by Sunderland (1945). Briefly, it has been shown that a peripheral nerve trunk receives a number of nutrient arteries from a main artery or a muscle artery, and these anastomose longitudinally within the nerve. Occlusion of one nutrient artery or its intraneural branches does not produce ischaemia as a good collateral circulation is available. Animal experiments (Adams, 1943; Roberts, 1948) have 
shown that it is necessary to occlude a number of vasa nervorum before significant ischaemia is produced. In cases of human peripheral arterial disease associated with nerve ischaemia it seems likely that occlusive changes in the vasa nervorum would produce a similar ischaemia, which may be increased by occlusion of a main artery in a limb. It is probable that such a degree of nerve ischaemia contributes in no small measure to the pain at rest typical of severe arterial disease, and may also be responsible in part for the onset of trophic skin changes.

The pathology of chronic ischaemic changes in peripheral nerves was first described by Joffroy and Achard (1889), and was later expanded by Buerger (1908) for cases of thrombo-angiitis obliterans, and by Priestley (1931) for arteriosclerotic limbs. These workers described patchy Wallerian-type degeneration in the nerve fibres, and endoneurial fibrosis, more marked distally than proximally. In particular, the nerve changes were found to be directly proportional to the degree of arteriosclerotic change in the vessels, suggesting a peripheral cause for the nerve degeneration which was probably ischaemia.

In our biopsies, there was evidence of extensive segmental demyelination and remyelination in addition to Wallerian degeneration and regeneration. These two types of change cannot be distinguished in ordinary transverse sections of the nerve, which may account for the earlier reports of patchy or slight degeneration in nerves subjected to considerable degrees of ischaemia.

Recently attention has been drawn to the occurrence of segmental demyelination in certain human peripheral neuropathies, such as those associated with diabetes (Thomas and Lascelles, 1965 and 1966a) and in the Guillain-Barré syndrome (Thomas and Lascelles, 1966b). It has also been demonstrated in experimental allergic neuritis (Waksman and Adams, 1956; Cragg and Thomas, 1964), in experimental diphtheritic neuropathy (McDonald, 1963), and in lead neuropathy (Fullerton, 1966) in animals. The evidence presented in this paper shows that chronic ischaemia also produces segmental demyelination, and the presence of this change therefore indicates that ischaemia does affect Schwann cells, either directly by anoxia or indirectly by accumulation of toxic metabolites.

Regenerating fibres that have undergone Wallerian-type degeneration are only recognizable as such by teasing methods when the regeneration process has reached a certain stage. Before this stage, it is not possible to distinguish between normal small myelinated fibres and those which have partially regenerated but have not yet regained their normal diameter. Figure 1 shows several fibres which have clearly undergone Wallerian-type degeneration and regeneration; the severity of the changes seen in transverse section (Fig. 3), however, suggests that axonal damage may be more widespread than would appear from the presence of regenerated fibres in the teased preparations. Since ample time had elapsed in these patients for regeneration of nerve fibres to occur, it seems likely that ischaemic neuropathy is a process in which axonal damage is not always followed by regeneration.

The relation between our findings and those occurring in old age must be considered. Cottrell (1940) observed occlusive changes in the vasa nervorum in old age, and showed that an increase in endoneurial collagen is associated with a decrease in the number of nerve fibres present. Lascelles and Thomas (1966) have shown that over the age of 65 years irregularities of internodal length occur, and are common in the older age groups. Evidence of both Wallerian-type degeneration and regeneration and segmental demyelination and remyelination was observed. The presence of the latter type of change may well be ischaemic in origin, consequent upon gradual vascular occlusion, in a similar manner to the changes produced in our patients.

It is well known that segmental demyelination and remyelination in a nerve produces a reduction in conduction velocity (McDonald, 1963; Cragg and Thomas, 1964; Gilliatt, 1966), and impairment, 8 particularly of those functions that depend upon the ability of the nerve to transmit a synchronous volleyt of impulses, namely, vibration sensitivity and the? tendon reflexes (Gilliatt and Willison, 1962; Lascelles and Thomas, 1966). As already mentioned, several workers have observed that in old age vibration sensitivity is impaired in the legs (Pearson, 1928), and that the tendon reflexes are diminished or lost, particularly the ankle jerks (Critchley, 1931). Similar changes were observed in many of our patients, supporting the view that loss of these functions in the aged is at least partially due to segmental demyelination in the nerve fibres resulting from peripheral ischaemia. Occlusive changes in the vasa nervorum of the aged may well contribute to the peripheral neuropathology of old age.

The question arises as to how far ischaemia contributes to the changes in the peripheral nerves of diabetic neuropathy. Although earlier workers (Woltman and Wilder, 1920; Dry and Hines, 1941) attributed diabetic neuropathy to peripheral arteriosclerosis, recent work has cast doubt upon this explanation (Dolman, 1963; Greenbaum, Richardson, Salmon, and Urich, 1964) and has suggested that the changes may be of metabolic origin. However, in patients with diabetic neuropathy and 
marked peripheral vascular disease it seems likely that ischaemia contributes to the segmental demyelination and to the loss of axons that is also encountered (Greenbaum et al., 1964; Thomas and Lascelles, 1966a). Dreyfus, Hakim, and Adams (1957) have put forward some evidence to suggest that the cause of the ocular palsies occasionally seen in association with diabetes may be ischaemia.

The electron microscopic findings in the present cases are of particular interest, as they provide additional evidence that occlusion of the more distal vessels of the arterial tree occurs in severe peripheral arteriosclerotic disease. Hitherto it has been generally believed that the smaller vessels in arteriosclerosis escape occlusive changes (Martin, Lynn, Dible, and Aird, 1956), in contrast to the situation in Buerger's disease, where the small vessels are affected first. Strandness, Nothstein, Alexander, and Bell (1960), however, reported intimal proliferation and thickening of the vessel wall, with occasional hyalinization, in arterioles in peripheral arteriosclerosis, and Cottrell (1940) found medial fibrosis and hyalinization in the vasa nervorum of the aged. Hyalinization of the media and necrosis of smooth muscle cells in arterioles occurs particularly in hypertension, but none of our patients was hypertensive and none showed clinical evidence of renal disease. Banson and Lacy (1964) found thickening of capillary basement membranes in diabetic and in some non-diabetic patients with peripheral arteriosclerosis. Evidence has been produced to show that basement proliferation and thickening may precede hyalinization, and that hyaline material may in fact arise from basement membranes (Smith, 1955; Wiener, Spiro, and Lattes, 1965). Smooth muscle cells are well known to occur in the intima of arteries under various pathological conditions, especially in large arteriosclerotic vessels. The changes in the vasa nervorum found in our patients may be indicative of primary vascular disease, or may be secondary to ischaemia, or to thrombosis more proximally. Further studies are needed on this point.

The presence of these changes in the vessels indicates that local ischaemia due to occlusion of the vasa nervorum may play an important part in determining the nerve damage. Our electron microscopic findings in the nerve fibres are probably non-specific, the presence of myelin figures in the Schwann cells and macrophages merely indicating that myelin has been broken down; the loss of large myelinated fibres is additional evidence for this. It is perhaps rather surprising that the specific changes of segmental demyelination were not seen in these electron micrographs, but there is no doubt that in these cases axons completely denuded of myelin were rare, most of the demyelinated regions having become at least thinly remyelinated.

\section{SUMMARY}

Thirty-two patients with obliterative arterial disease of the lower limbs were examined neurologically. Evidence of sensory peripheral neuropathy was found in $87.5 \%$.

Sural nerve biopsies from eight patients were obtained immediately before amputation. Isolated nerve fibres were examined in five of the biopsies, and these showed evidence of segmental demyelination and remyelination and of Wallerian-type degeneration and regeneration. Transverse sections revealed loss of myelinated fibres.

The eight nerve biopsies were examined with the electron microscope. Degenerative changes were found in the nerves, and the small arterial vessels of the epineurium showed marked occlusive changes with intimal thickening and medial degeneration and fibrosis. Perivascular connective tissue was increased on all vessels, and the basement membranes were proliferated and thickened.

The nature and implications of these changes, and their relation to old age and to other neuropathies, particularly diabetic, are discussed.

We wish to thank Professor W. T. Irvine for permission to examine and biopsy his patients, and to publish our findings, and Mr. A. E. Thompson and Mr. J. T. Hobbs for their cooperation and help during the amputations.

We would also like to express our gratitude to Professor F. Goldby for the use of the electron microscope, for the facilities of the Anatomy Department in which most of the work was done, and for useful discussion; to the Wellcome Trust for providing the electron microscope; and to the Dowager Countess Eleanor Peel Trust for the ultramicrotome.

Finally we are grateful to Professor R. W. Gilliatt and to Dr. P. K. Thomas for much helpful criticism and advice, and to Mr. R. J. Fant for the photographs.

\section{REFERENCES}

Adams, W. E. (1942). The blood supply of nerves: I. Historical review. J. Anat. (Lond.), 76, 323-341.

- (1943). The blood supply of nerves: II. The effects of exclusion of its regional sources of supply on the sciatic nerve of the rabbit. Ibid., 77, 243-250.

Banson, B. B., and Lacy, P. E. (1964). Diabetic microangiopathy in human toes; with emphasis on the ultrastructural change in dermal capillaries. Amer. J. Path., 45, 41-58.

Bentley, F. H., and Schlapp, W. (1943). Experiments on the blood supply of nerves. J. Physiol. (Lond.), 102, 62-71.

Blackwood, W. (1944). A pathologist looks at ischaemia. Edinb. med. J., 51, 131-143.

Buerger, L. (1908). Thrombo-angiitis obliterans: a study of the vascular lesions leading to presenile spontaneous gangrene. Amer. J. med. Sci., 136, 567-580.

Cottrell, L. (1940). Histologic variations with age in apparently normal peripheral nerve trunks. Arch. Neurol. Psychiat. (Chic.), 43, $1138-1150$. 
Cragg, B. G., and Thomas, P. K. (1964). Changes in nerve conduction in experimental allergic neuritis. J. Neurol. Neurosurg. Psychiat., 27, 106-115.

Critchley, M. (1931). The neurology of old age. II. Clinical manifestations in old age. Lancet, 1, 1221-1230.

Dolman, C. L. (1963). The morbid anatomy of diabetic neuropathy. Neurology (Minneap.), 13, 135-142.

Dreyfus, P. M., Hakim, S., and Adams, R. D. (1957). Diabetic ophthalmoplegia; report of a case, with postmortem study and comments on vascular supply of human oculomotor nerve. Arch. Neurol. Psychiat. (Chic.), 77, 337-349.

Dry, T. J., and Hines, E. A. (1941). The rôle of diabetes in the development of degenerative vascular disease: with special reference to the incidence of retinitis and peripheral neuritis. Ann. intern. Med., 14, 1893-1902.

Fullerton, P. M. (1966). Chronic peripheral neuropathy produced by lead poisoning in guinea-pigs. $J$. Neuropath. exp. Neurol., 25, 214-236.

—, Gilliatt, R. W., Lascelles, R. G., and Morgan-Hughes, J. A. (1965). The relation between fibre diameter and internodal length in chronic neuropathy. J. Physiol. (Lond.), 178, 26-28P.

Gairns, F. W., Garven, H. S. D., and Smith, G. (1960). The digital nerves and the nerve endings in progressive obliterative vascular disease of the leg. Scot. med. J., 5, 382-391.

Gamble, H. J., and Eames, R. A. (1964). An electron microscope study of the connective tissues of human peripheral nerve. J. Anat. (Lond.), 98, 655-663.

Gilliatt, R. W. (1966). Nerve conduction in human and experimental neuropathies. Proc. roy. Soc. Med., 59, 989-993.

- and Willison, R. G. (1962). Peripheral nerve conduction in diabetic neuropathy. J. Neurol. Neurosurg. Psychiat., 25, 11-18.

Gombault, A. (1880). Contribution à l'étude anatomique de la névrite parenchymateuse subaiguë et chronique-névrite segmentaire péri-axile. Arch. Neurol. (Paris), 1, 11-38, 177-190.

Greenbaum, D., Richardson, P. C., Salmon, M. V., and Urich, H. (1964). Pathological observations on 6 cases of diabetic neuropathy. Brain, 87, 201-214.

Gutmann, E., and Sanders, F. K. (1943). Recovery of fibre numbers and diameters in the regeneration of peripheral nerves. $J$. Physiol. (Lond.), 101, 489-518.

Haimovici, H. (1950). Peripheral arterial embolism; a study of 330 unselected cases of embolism of the extremities. Angiology, 1, 20-45.

Holmes, W., Highet, W. B., and Seddon, H. J. (1944). Ischaemic nerve lesions occurring in Volkmann's contracture. Brit. J. Surg., 32, 259-275.

Hutchinson, E. C., and Liversedge, L. A. (1956). Neuropathy in peripheral vascular disease. Quart. J. Med., 25, 267-274.

Joffroy, A., and Achard, C. (1889). Névrite périphérique d'origine vasculaire. Arch. Méd. exp., 1, 229-240 (cited by Richards, 1951).

Kernohan, J. W., and Woltman, H. W. (1938). Periarteritis nodosa a clinicopathologic study with special reference to the nervous system. Arch. Neurol. Psychiat. (Chic.), 39, 655-686.

Lascelles, R. G., and Thomas, P. K. (1966). Changes due to age in internodal length in the sural nerve in man. J. Neurol. Neurosurg. Psychiat., 29, 40-44.

Lewis, T., Pickering, G. W., and Rothschild, P. (1931). Centripetal paralysis arising out of arrested bloodflow to the limb, including notes on a form of tingling. Heart, 16, 1-32.
Lubińska, L. (1958). 'Intercalated' internodes in nerve fibres. Nature (Lond.), 181, 957-958.

- (1959). Region of transition between preserved and regenerating parts of myelinated nerve fibers. J. comp. Neurol., 113, 315-335.

Martin, P., Lynn, R. B., Dible, J. H., and Aird, I. (Editors) (1956). Peripheral Vascular Disorders. Livingstone, Edinburgh and London.

McDonald, W. I. (1963). The effects of experimental demyelination on conduction in peripheral nerve: A histological and electrophysiological study. I. Clinical and histological observations. II. Electrophysiological observations. Brain, 86, 481-500, and 501-524.

Mufson, I. (1952). Diagnosis and treatment of neural complications of peripheral arterial obliterative disease. Angiology, 3, 392-396.

O'Sullivan, D. J. (1966). Personal communication.

Pearson, G. H. J. (1928). Effect of age on vibratory sensibility. Arch. Neurol. Psychiat. (Chic.), 20, 482-496.

Porter, E. L., and Wharton, P. S. (1949). Irritability of mammalian nerve following ischemia. J. Neurophysiol., 12, 109-116.

Priestley, J. B. (1931). The histopathology of peripheral nerves removed from extremities amputated for arteriosclerotic gangrene. Proc. Mayo Clin., 6, 517-518.

Richards, R. L. (1951). Ischaemic lesions of peripheral nerves: a review. J. Neurol. Neurosurg. Psychiat., 14, 76-87.

Roberts, J. T. (1948). The effect of occlusive arterial diseases of the extremeties on the blood supply of nerves; experimental and clinical studies on the role of the vasa nervorum. Amer. Heart J., 35, 369-392.

Smith, J. P. (1955). Hyaline arteriolosclerosis in the kidney. J. Path. Bact., 69, 147-168.

Strandness, D. E., Nothstein, D. L., Alexander, J. A., and Bell, J. W. (1960). Observations on arteriolar disease in arteriosclerosis obliterans. Surgery, 47, 953-958.

Sunderland, S. (1945). Blood supply of the nerves of the upper limb in man. Arch. Neurol. Psychiat. (Chic.), 53, 91-115.

Thomas, P. K., and Young, J. Z. (1949). Internode lengths in the nerves of fishes. J. Anat. (Lond.), 83, 336-350. and Lascelles, R. G. (1965). Schwann-cell abnormalities in diabetic neuropathy. Lancet, 1, 1355-1357.

(1966a). The pathology of diabetic neuropathy. Quart. J. Med., 35, 489-509.

(1966b). Personal communication.

Tinel, J. (1917). Nerve Wounds. Translated by F. Rothwell; edited by C. Joll. Baillière, Tindall, and Cox, London.

Vizoso, A. D. (1950). Relation between internodal length and growth in human nerves. J. Anat. (Lond.), 84, 342-353.

- , and Young, J. Z. (1948). Internode length and fibre diameter in degenerating and regenerating nerves. Ibid., 82, 110-134.

Waksman, B. H., and Adams, R. D. (1956). Symposium on peripheral neuropathies: A comparative study of experimental allergic neuritis in the rabbit, guinea pig, and mouse. J. Neuropath exp. Neurol., 15, 293-333.

Wiener, J., Spiro, D., and Lattes, R. G. (1965). The cellular pathology of experimental hypertension. II. Arteriolar hyalinosis and fibrinoid change. Amer. J. Path., 47, 457-485.

Woltman, H. W., and Wilder, R. M. (1929). Diabetes mellitus: pathologic changes in the spinal cord and peripheral nerves. Arch. intern. Med., 44, 576-603. 